\title{
DUAL LIFE OF TPPP/p25 EVOLVED AT PHYSIOLOGICAL AND PATHOLOGICAL CONDITIONS
}

\author{
Judit Oláh and Judit Ovádi \\ Institute of Enzymology, Research Centre for Natural Sciences, \\ Hungarian Academy of Sciences, H-1117, Budapest, Hungary
}

\begin{abstract}
Address correspondence to: Judit Ovádi, Institute of Enzymology, Research Centre for Natural Sciences, Hungarian Academy of Sciences, Budapest, Magyar tudósok körútja 2., H-1117, Hungary, Tel. (36-1) 3826-714; E-mail: ovadi.judit@ttk.mta.hu

E-mail addresses:

J. Oláh: olah.judit@ttk.mta.hu;

J. Ovádi: ovadi.judit@ttk.mta.hu;
\end{abstract}

\begin{abstract}
Neomorphic Moonlighting Proteins perform distinct functions at physiological and pathological conditions without alterations at gene level. The disordered Tubulin Polymerization Promoting Protein (TPPP/p25), a prototype of Neomorphic Moonlighting Proteins, modulates the dynamics and stability of the microtubule system via its bundling and tubulin acetylation promoting activities. These physiological functions are mediated by its direct associations with tubulin/microtubules as well as tubulin deacetylases such as HDAC6. In normal brain TPPP/p25 is expressed in oligodendrocytes and plays a crucial role in the formation of projections in the course of differentiation requested for axon ensheathment. At pathological conditions TPPP/p25 interacts with alpha-synuclein, forms aberrant protein-protein interaction resulting in aggregation leading to the formation of inclusions as clinical symptoms. The co-enrichment and co-localization of TPPP/p25 and alpha-synuclein were established in human brain inclusions characteristic for Parkinson's disease and other synucleinopathies. The binding segments on TPPP/p25 involved in the physiological and pathological interactions were identified and validated at molecular and cell levels using recombinant proteins and transfected $\mathrm{HeLa}$ and inducible CHO10 cells expressing TPPP/p25. Our finding that distinct motives are responsible for the neomorphic moonlighting feature of TPPP/p25 has powerful innovative impact in anti-Parkinson drug research.
\end{abstract}

\section{KEYWORDS}

TPPP/p25, tubulin, alpha-synuclein, moonlighting, acetylation, Parkinson's disease

\section{NEOMORPHIC MOONLIGHTING PROTEINS}

The recognition that there are proteins with more than one function was recognized two decades ago and this characteristic was termed as moonlighting [1]. These proteins perform multiple, independent functions that are not coded at gene level, do not stem from genetic alterations (gene fusion or splice variants), their functions are manifested themselves at protein level. The functions of these moonlighting proteins can vary as a consequence of changes in cellular localization, cell type, and their oligomeric state, concentrations of substrates, cofactors or products [1]. In addition to these types of proteins, in which all functions are considered „normal”, there are proteins displaying a second function that is not considered as a „normal" one [2]. These are Neomorphic Moonlighting Proteins, physiological function of which can be converted into a pathological one mostly due to their hetero-associations with "pathological" partners distinct from the physiological ones [2,3].

The major part of the intracellular proteins has well-defined secondary and tertiary structures; however, a number of in silico and experimental data have been accumulated indicating that a part of proteins does not bear well-defined 3D structure [4-6]. These proteins denoted as intrinsically unstructured or disordered proteins, are rather common in living cells and fulfill essential physiological functions $[4,5]$. These functions are linked to 
their structural states, interactions with other cellular targets. Many disordered proteins also play crucial roles in the etiology of distinct conformational diseases such as multiple system atrophy (MSA), Parkinson's (PD) and Alzheimer's diseases [6-8], thus the Neomorphic Moonlighting Function is rather common for disordered proteins hallmarking conformational diseases; the prototype of these proteins is the TPPP/p25.

\section{CONSTRUCTION OF THE DISORDERED TPPP/p25}

Tubulin Polymerization Promoting Protein (TPPP/p25) is a disordered, brain specific protein (http://www.genenames.org/data/hgnc data.php?hgnc id=24164), its main target is the tubulin/microtubule system $[9,10]$. Prediction methods established for the disordered proteins and circular dichroism (CD) spectroscopy indicated more than one decade ago that TPPP/p25 does not have a well-defined 3D structure [9, 11]. This finding was questioned and it was stated that it is a folded protein [12], however, multinuclear NMR studies as well as limited proteolysis provided evidence that extended unstructured segments at the N- (45aa) and C- (44aa) termini are straddling a flexible CORE region (130 aa) [13]. Most peaks of the ${ }^{1} \mathrm{H}-{ }^{15} \mathrm{~N}$ HSQC spectrum of the human recombinant protein appeared to be sharp and poorly dispersed, predominantly fall in a narrow cca. $0.6 \mathrm{ppm}{ }^{1} \mathrm{H}$ region $(7.9-8.5 \mathrm{ppm})$, a feature characteristic for intrinsically unstructured and highly dynamic proteins supporting that a large portion of the protein fluctuates among multiple conformations and lacks a welldefined 3D structure. TPPP/p25 occurs both in monomeric and homodimeric forms, the dimer has been found to be more compact as expected from the assembly of the highly disordered monomers [14].

The middle CORE segment comprises a couple key binding motives/segments responsible for the interactions with ligands, peptides and proteins [15]; while the unfolded N-terminal includes phosphorylation sites [16].

\section{MULTIPLE INTERACTIONS WITH LIGANDS, PEPTIDES AND PROTEINS}

GTP There is a representative set of GTP binding sequence motives (consensus sequences) [17-19], one of these motives was identified within the CORE segment of TPPP/p25 $\left(\mathrm{G}^{68}-(\mathrm{X})_{4} \mathrm{GK}\right)$, as a potential binding segment responsible for GTP binding [13]. GTP binding to the disordered protein was established by affinity chromatography, fluorescence spectroscopy and size exclusion gel chromatography [13]. This latter technique rendered it possible to detect the GTP's positive effect on the dimerization of TPPP/p25, which resulted in the rearrangement of the unfolded monomers into relatively compact dimeric species resulting in a more pronounced tubulin polymerization promoting potency (Fig. 1) [14]. The GTP-induced structural alterations could be prerequisite for the catalytic activity of the disordered TPPP/p25. Indeed, this protein specifically hydrolyses GTP, but not ATP, in a $\mathrm{Mg}^{2+}$-dependent manner as proved by $\mathrm{P}^{31}$-NMR spectroscopy as well as by malachite green phosphate release assay (Fig. 1) [13]. The detected GTPase activity is comparable with the intrinsic activities of small $G$ proteins, which may incline one to search for regulatory GTPase activating proteins promoting a more pronounced activity.

ZINC Zinc is a ubiquitous and essential micronutrient and is intimately linked to health as well as a number of disease states [20-24]. Zinc is involved in an extraordinary range of biological functions and is essential for growth, development and for a host of diseases, although its precise role is not fully understood. The bivalent zinc cation has been identified as a ligand that can induce considerable rearrangement of the recombinant human TPPP/p25 at relatively low protein concentration (Fig. 1) [25]. This finding suggested that the partial folding of TPPP/p25 caused by zinc binding to the zinc finger motif $\left(\mathrm{H}_{2} \mathrm{C}_{2}\right)\left(\mathrm{H}^{61}-\mathrm{C}^{83}\right)$ may have physiological relevance. The specific binding of the $\mathrm{Zn}^{2+}$ to TPPP/p25 induced molten globule formation, which is a partially folded structure accommodating the zinc binding motif localized at the single $\mathrm{W}^{76}$-containing region as demonstrated by fluorescence resonance energy transfer and quenching experiments [25]. The $\mathrm{Zn}^{2+}-$ induced change reduced the GTPase activity, but enhanced the tubulin promoting activity of TPPP/p25 ([25], therefore, the structural alterations were coupled with functional ones (Fig. 1). 
TUBULIN Microtubules, one of the major constituents of the cytoskeleton, are hollow cylinders formed by polymerization of $\alpha$ and $\beta$ tubulin dimers, their stability are ensured by microtubule associated proteins (MAPs) and ligands such as GTP. TPPP/p25 belongs to a new and unique family of MAPs and its primary target is the tubulin/microtubule system $[9,10,26]$. The binding of TPPP/p25 to tubulin is coupled with significant conformational changes which are likely resulted from the structural arrangement mostly in the unstructured TPPP/p25 rather than in the tubulin with a well-defined 3D structure $[9,11]$. A number of in vitro studies with human recombinant protein and with isolated one from bovine brain have shown that this protein displays high potency to induce tubulin assembly coupled with bundling activity (Fig. 1) ([15] and references therein). Pelleting (differential binding) and tubulin polymerization assay showed that the $\mathrm{N}$ - and/or C-terminalfree (predominantly the latter one) truncated protein forms displayed extensively reduced tubulin binding and tubulin polymerization potency as compared to the full length species, in addition no microtubule bundling was induced by the $\mathrm{C}$-terminal free and the double truncated protein species suggesting that the disordered termini contribute to the formation of the microtubule ultrastructures likely by their cross-linking potency [3]. These results are in agreement with the $\mathrm{CD}$ measurements, and provided additional evidence for the key role of the $\mathrm{C}$ terminus in the tubulin-related processes.

PHOSPHORYLATION As we have demonstrated a decade ago by atomic force microscopy and electron microscopy, TPPP/p25 is able to promote the formation of intact-like microtubules with its extensive bundling activity $[9,10]$. The in vitro phosphorylationof TPPP/p25 by specific protein kinases at $\mathrm{T}^{14}, \mathrm{~S}^{18}$ and $S^{160}$ (by cyclin-dependent kinase 5), $S^{18}$ and $S^{160}$ (by extracellular signal-regulated kinase 2 (ERK2)) and $S^{32}$ (by cAMP-dependent protein kinase A) led to structural and functional changes [16]. In fact, the kinase-mediated modification of TPPP/p25 (2.9 mol Pi/mol protein) completely blocked its tubulin polymerization promoting potency (Fig. 1); however, cAMP-dependent protein kinase A was ineffective. The partially phosphorylated (1.3 mol Pi/mol protein) TPPP/p25 exhibited low tubulin polymerization activity; transmission electron microscopy showed that, in sharp contrast to the control, the sample mainly consisted of thread-like oligomers [16]. These data that the phosphorylation strongly impedes the ability of TPPP/p25 to promote the formation and bundling of intact microtubules as well as to mediate the formation of large tubulin-TPPP/p25 aggregates likely have physiological significance since the three N-terminal sites were found to be phosphorylated in vivo in TPPP/p25 isolated from bovine brain due to its direct association of with ERK2 [16].

\section{FUNCTIONS WITH PHYSIOLOGICAL RELEVANCE}

The eukaryotic cytoskeleton consisting of three filamentous systems displays various intracellular functions due to its dynamic reorganizing ability. The filamentous structures are highly variable in different cells and tissues, for example, the precise regulation of microtubule dynamics is critical for cell cycle progression, cell signaling, intracellular transport and cell polarization. Their dynamic reorganizing ability shows great variability depending on the functions which are attained by static and dynamic associations of macromolecules and ligands and post-translational modifications [27]. These characteristics of the microtubule system have been analyzed by microscopy of microinjected or expressed fluorescent tubulin, time-lapse microscopy and analysis of timedependent microtubule length changes [28]. One of our early observations was that TPPP/p25 inhibited the microtubule-derived mitosis in Drosophila embryos expressing tubulin-GFP fusion protein as monitored by confocal microscopy following microinjection of recombinant TPPP/p25; this effect was abolished when TPPP/p25 was injected with GTP into the embryo [10].

The tubulin subunits are subjected to a number of post-translational modifications, such as acetylation, phosphorylation, tyrosination, polyglycylation and polyglutamylation. Notably, the reversible post-translational acetylation of $\alpha$-tubulin at residue Lys-40 modifies the dynamics of microtubule system ([29] and references therein). Protein deacetylases, like histone deacetylases (HDACs) remove acetyl groups; uniquely among the HDACs, HDAC6 and $\mathrm{NAD}^{+}$-dependent deacetylase sirtuin-2 have cytoplasmic localization and their inhibition by specific inhibitors such as Trichostatin A and AGK2, respectively, increases the intracellular level of acetylated tubulin and alters cell motility. TPPP/p25 interacts with the tubulin deacetylase enzyme, HDAC6, inhibits its deacetylase activity and thus it plays a role in the control of the acetylation level of microtubules [29]. 
These features of TPPP/p25 are related to its physiological functions, namely the modulation and coordination of the dynamics and stability of microtubule network by it extensive microtubule bundling and tubulin acetylation enhancing activities (Fig. 2) [9, 10, 29]. Previously we have provided evidence that TPPP/p25 co-localizes with the microtubule network and enhances its stability in different cell lines expressing TPPP/p25 either endogenously (CG-4 cells), ectopically (CHO10 cells by doxycycline induction) or due to transient transfection (HeLa cells) as visualized by immunofluorescence microscopy [26, 29, 30]. The microtubule network bundled by TPPP/p25 displayed resistance against anti-microtubular agents such as vinblastine or nocodazole revealing the enhanced stability of the network $[26,29,30]$. Transiently transfected HeLa cells expressing full length or truncated EGFP-TPPP/p25 showed that the truncated protein - in contrast to the full-length one - distributed homogeneously in the cytosol underlining the crucial role of the unstructured termini in the association of TPPP/p25 to the microtubule network [3].

We established that the proteasome machinery is the main, if not exclusive, degrading system responsible for the elimination of the disordered unbound TPPP/p25 [26, 31] as described for many intrinsically unstructured proteins [32-34]. Their degradations are inhibited by MG132, a well-established inhibitor of proteasome, which further suggests the involvement of the proteasome machinery in their degradation [32].

In brain, microtubules are of special importance since they are actively involved in the maintenance of structural polarity of neurons which is crucial for their physiological functions [35]. The thin, long ax ons of neurons are decorated by MAPs and ensheathed by differentiated oligodendrocytes [36]. In fact, physiologically TPPP/p25 is expressed mainly in the oligodendrocytes [371 of brain and plays a crucial role in their differentiation process [38]. The enhanced stability of the TPPP/p25-bundled microtubules has specific importance in the course of differentiation of the oligodendrocytes, where TPPP $/ \mathrm{p} 25$ contributes to the formation of the projections (Fig. 3) [38]. Oligodendrocyte cells accumulate $\mathrm{Zn}^{2+}$; in myelinating oligodendrocytes the intracellular $\mathrm{Zn}^{2+}$ concentration has been found to be relatively high $(50 \mu \mathrm{M})[39,40]$. Our results showed that the $\mathrm{Zn}^{2+}$-induced structural change can enhance the intracellular level of the disordered TPPP/p25 by counteracting its proteasomal degradation (Attila Lehotzky, Judit Oláh, Sándor Szunyogh, Adél Szabó, Tímea Berki, Judit Ovádi, submitted manuscript), which could be essential for the extension of projections playing role in the maintenance of the stability of the zinc-rich myelin sheath in the central nervous system (CNS). This is an important issue since both the enrichment and the lack of this protein leads to CNS diseases such as MSA [41] and glioma [42], respectively.

\section{FUNCTIONS WITH PATHOLOGICAL RELEVANCE}

Since in normal human brain TPPP/p25 is expressed in oligodendrocytes [37, 38], which are the major constituent of the ensheathment of axons; destruction of this process results in defects of myelin sheaths and remyelinization leading to the development of multiple sclerosis (MS) [43]. The amount of TPPP/p25 in oligodendrocytes and demyeliniated lesions of human brain from MS patients revealed loss of TPPP/p25positive oligodendrocytes within the plaques (Fig. 3) [43]. The analysis of cerebrospinal fluid samples of MS patients showed significant increase of TPPP/p25 for patients with clinically isolated and relapsing remitting MS syndromes (Fig. 3) [44].

The optimal intracellular expression of TPPP/p25 is a key factor for the physiology of the brain functions; the lack and enrichment of TPPP/p25 in oligodendrocytes lead to distinct CNS diseases: glioma [42] and MSA [41], respectively, (Fig. 3). MSA is a progressive neurodegenerative disorder presenting various combinations of parkinsonism, cerebellar ataxia, corticospinal and autonomic dysfunction ([45] and references therein). Co-enrichment and co-localization of the two disordered hallmark proteins, TPPP/p25 and alphasynuclein, in human inclusions have been reported in the case of MSA and other synucleinopathies [41]. The global pathomechanism of these neurological disorders denoted as conformational disease is the following: they are initiated by unfolded/misfolded proteins (TPPP/p25, alpha-synuclein), which enter into pathological interactions (TPPP/p25-alpha-synuclein complex) forming aggregates leading to inclusion formation appearing as clinical symptoms.

TPPP/p25, as a Neomorphic Moonlighting Protein, is involved in interaction with deacetylase HDAC6 at pathological condition as well and plays a crucial role in aggresome formation [46-48]. The aggresome 
formation is a self-protecting mechanism against the toxic, small aggregates localized at the periphery of the cells which are actively transported on the acetylated microtubule network to the centrosome region [49]. Aggresome formation has been produced by over-expression of TPPP/p25 in transfected HeLa cells which is considered as an appropriate model to study the pathomechanism of inclusion formation as well as to test potential anti-aggregation agents [26]. The oligodendroglial degeneration was studied in HEK293T and KG1C cells which ectopically expressed alpha-synuclein and TPPP/p25 [45]. Co-immunoprecipitation analysis revealed the specific interaction of TPPP/p25 and alpha-synuclein followed by the acceleration of alphasynuclein oligomerization. It has been documented that $\mathrm{NAD}^{+}$-dependent deacetylase sirtuin-2 rescues alphasynuclein-mediated oligodendrocyte cell death coupled with increased protein aggregation; it was most prominent in AGK2-treated cells co-transfected with TPPP/p25 and alpha-synuclein [45].

Concerning the etiology of PD and MSA, there is an open question regarding the co-enrichment of TPPP/p25 and alpha-synuclein in Lewy bodies and glial inclusion, respectively. The co-localization of these two disordered proteins was demonstrated in 2004 [41], which was followed by a couple of others [45, 50-52]. In normal brain these two proteins are expressed in different cell types of the human brain (TPPP/p25 in oligodendrocytes, alpha-synuclein in neurons); however, there is no clear information how the inclusions with their co-aggregations could be formed. A plausible way is that these poteins could enter into the diseased cells from the extracellular matrix; this idea comes from our recent observation that, like alpha-synuclein [53], TPPP/p25 could be also taken up by cells from the extracellular volume [3]. This situation, on the other hand, has important innovative aspects concerning the evaluation of specific anti-synucleinopathy agents which target the interface of the pathological, but not the physiological complex of TPPP/p25.

\section{ABBREVIATIONS}

central nervous system, CNS; circular dichroism, CD; extracellular signal-regulated kinase 2, ERK2; histone deacetylase, HDACs; multiple system atrophy, MSA; microtubule associated protein, MAP; multiple sclerosis, MS; Parkinson's disease, PD; Tubulin Polymerization Promoting Protein, TPPP/p25;

\section{ACKNOWLEDGEMENTS}

This work was supported by the European Commission [(DCI ALA/19.09.01/10/21526/ 245297/ALFA 111(2010)29], European Concerted Research Action [COST Action TD0905]; Hungarian National Scientific Research Fund Grants OTKA T-101039 and Richter Gedeon Nyrt (4700147899) to J. Ovádi. The funding body had no role in design, collection, analysis and interpretation of data, or in the writing of the manuscript.

\section{REFERENCES}

1 Jeffery, C. J. (1999) Moonlighting proteins. Trends Biochem. Sci. 24, 8-11

2 Jeffery, C. J. (2011) Proteins with neomorphic moonlighting functions in disease. IUBMB Life 63, 489494

3 Tőkési, N., Oláh, J., Hlavanda, E., Szunyogh, S., Szabó, A., Babos, F., Magyar, A., Lehotzky, A., Vass, E. and Ovádi, J. (2014) Identification of motives mediating alternative functions of the neomorphic moonlighting TPPP/p25. Biochim. Biophys. Acta 1842, 547-557

$4 \quad$ Fink, A. L. (2005) Natively unfolded proteins. Curr. Opin. Struct. Biol. 15, 35-41

5 Dunker, A. K., Silman, I., Uversky, V. N. and Sussman, J. L. (2008) Function and structure of inherently disordered proteins. Curr. Opin. Struct. Biol. 18, 756-764

6 Uversky, V. N. (2002) What does it mean to be natively unfolded? Eur. J. Biochem. 269, 2-12

7 Irvine, G. B., El-Agnaf, O. M., Shankar, G. M. and Walsh, D. M. (2008) Protein aggregation in the brain: the molecular basis for Alzheimer's and Parkinson's diseases. Mol. Med. 14, 451-464

8 Taylor, J. P., Hardy, J. and Fischbeck, K. H. (2002) Toxic proteins in neurodegenerative disease. Science 296, 1991-1995 
Hlavanda, E., Kovács, J., Oláh, J., Orosz, F., Medzihradszky, K. F. and Ovádi, J. (2002) Brain-specific p25 protein binds to tubulin and microtubules and induces aberrant microtubule assemblies at substoichiometric concentrations. Biochemistry 41, 8657-8664

Tirián, L., Hlavanda, E., Oláh, J., Horváth, I., Orosz, F., Szabó, B., Kovács, J., Szabad, J. and Ovádi, J. (2003) TPPP/p25 promotes tubulin assemblies and blocks mitotic spindle formation. Proc. Natl. Acad. Sci. U S A 100, 13976-13981

Orosz, F., Kovács, G. G., Lehotzky, A., Oláh, J., Vincze, O. and Ovádi, J. (2004) TPPP/p25: from unfolded protein to misfolding disease: prediction and experiments. Biol. Cell 96, 701-711

Otzen, D. E., Lundvig, D. M., Wimmer, R., Nielsen, L. H., Pedersen, J. R. and Jensen, P. H. (2005) p25alpha is flexible but natively folded and binds tubulin with oligomeric stoichiometry. Protein Sci. 14, 1396-1409

Zotter, A., Bodor, A., Oláh, J., Hlavanda, E., Orosz, F., Perczel, A. and Ovádi, J. (2011) Disordered TPPP/p25 binds GTP and displays $\mathrm{Mg}(2+)$-dependent GTPase activity. FEBS Lett. 585, 803-808

Oláh, J., Zotter, A., Hlavanda, E., Szunyogh, S., Orosz, F., Szigeti, K., Fidy, J. and Ovádi, J. (2012) Microtubule assembly-derived by dimerization of TPPP/p25. Evaluation of thermodynamic parameters for multiple equilibrium system from ITC data. Biochim. Biophys. Acta 1820, 785-794

Oláh, J., Tőkési, N., Lehotzky, A., Orosz, F. and Ovádi, J. (2013) Moonlighting microtubule-associated proteins: regulatory functions by day and pathological functions at night. Cytoskeleton (Hoboken) 70, 677-685

Hlavanda, E., Klement, E., Kokai, E., Kovacs, J., Vincze, O., Tőkési, N., Orosz, F., Medzihradszky, K. F., Dombradi, V. and Ovádi, J. (2007) Phosphorylation blocks the activity of tubulin polymerizationpromoting protein (TPPP): identification of sites targeted by different kinases. J. Biol. Chem. 282, 29531-29539

Dever, T. E., Glynias, M. J. and Merrick, W. C. (1987) GTP-binding domain: three consensus sequence elements with distinct spacing. Proc. Natl. Acad. Sci. U S A 84, 1814-1818

Bourne, H. R., Sanders, D. A. and McCormick, F. (1991) The GTPase superfamily: conserved structure and molecular mechanism. Nature 349, 117-127

19 Sprang, S. R. (1997) G protein mechanisms: insights from structural analysis. Annu. Rev. Biochem. 66, 639-678

Berg, J. M. and Shi, Y. (1996) The galvanization of biology: a growing appreciation for the roles of zinc. Science 271, 1081-1085

Law, W., Kelland, E. E., Sharp, P. and Toms, N. J. (2003) Characterisation of zinc uptake into rat cultured cerebrocortical oligodendrocyte progenitor cells. Neurosci. Lett. 352, 113-116

Mocchegiani, E., Bertoni-Freddari, C., Marcellini, F. and Malavolta, M. (2005) Brain, aging and neurodegeneration: role of zinc ion availability. Prog. Neurobiol. 75, 367-390

Murakami, M. and Hirano, T. (2008) Intracellular zinc homeostasis and zinc signaling. Cancer Sci. 99, $1515-1522$

Zotter, A., Oláh, J., Hlavanda, E., Bodor, A., Perczel, A., Szigeti, K., Fidy, J. and Ovádi, J. (2011) $\mathrm{Zn}(2)+$-induced rearrangement of the disordered TPPP/p25 affects its microtubule assembly and GTPase activity. Biochemistry 50, 9568-9578

Lehotzky, A., Tirián, L., Tőkési, N., Lénárt, P., Szabó, B., Kovács, J. and Ovádi, J. (2004) Dynamic targeting of microtubules by TPPP/p25 affects cell survival. J. Cell. Sci. 117, 6249-6259

Conde, C. and Caceres, A. (2009) Microtubule assembly, organization and dynamics in axons and dendrites. Nat. Rev. Neurosci. 10, 319-332

Kamath, K., Oroudjev, E. and Jordan, M. A. (2010) Determination of microtubule dynamic instability in living cells. Methods Cell. Biol. 97, 1-14 
Lehotzky, A., Tőkési, N., Gonzalez-Alvarez, I., Merino, V., Bermejo, M., Orosz, F., Lau, P., Kovacs, G. G. and Ovádi, J. (2008) Progress in the development of early diagnosis and a drug with unique pharmacology to improve cancer therapy. Philos. Transact. A. Math. Phys. Eng. Sci. 366, 3599-3617

Goldbaum, O., Jensen, P. H. and Richter-Landsberg, C. (2008) The expression of tubulin polymerization promoting protein TPPP/p25alpha is developmentally regulated in cultured rat brain oligodendrocytes and affected by proteolytic stress. Glia 56, 1736-1746

Melo, S. P., Barbour, K. W. and Berger, F. G. (2011) Cooperation between an intrinsically disordered region and a helical segment is required for ubiquitin-independent degradation by the proteasome. $\mathrm{J}$. Biol. Chem. 286, 36559-36567

Suskiewicz, M. J., Sussman, J. L., Silman, I. and Shaul, Y. (2011) Context-dependent resistance to proteolysis of intrinsically disordered proteins. Protein Sci. 20, 1285-1297

Tsvetkov, P., Myers, N., Moscovitz, O., Sharon, M., Prilusky, J. and Shaul, Y. (2012) Thermo-resistant intrinsically disordered proteins are efficient 20S proteasome substrates. Mol. Biosyst. 8, 368-373

Neukirchen, D. and Bradke, F. (2011) Neuronal polarization and the cytoskeleton. Semin. Cell. Dev. Biol. 22, 825-833

Bauer, N. G., Richter-Landsberg, C. and Ffrench-Constant, C. (2009) Role of the oligodendroglial cytoskeleton in differentiation and myelination. Glia 57, 1691-1705

37 Takahashi, M., Tomizawa, K., Fujita, S. C., Sato, K., Uchida, T. and Imahori, K. (1993) A brain-specific protein p25 is localized and associated with oligodendrocytes, neuropil, and fiber-like structures of the CA hippocampal region in the rat brain. J. Neurochem. 60, 228-235

Lehotzky, A., Lau, P., Tőkési, N., Muja, N., Hudson, L. D. and Ovádi, J. (2010) Tubulin polymerization-promoting protein (TPPP/p25) is critical for oligodendrocyte differentiation. Glia 58, $157-168$

Iyengar, G. V., Kasperek, K. and Feinendegen, L. E. (1978) Retention of the metabolized trace elements in biological tissues following different drying procedures. I. Antimony, cobalt, iodine, mercury, selenium and zinc in rat tissues. Sci. Total Environ. 10, 1-16

40 Koh, J. Y. (2001) Zinc and disease of the brain. Mol. Neurobiol. 24, 99-106

41 Kovacs, G. G., Laszló, L., Kovács, J., Jensen, P.H., Lindersson, E., Botond, G., Molnar, T., Perczel, A., Hudecz, F., Mezo, G., Erdei, A., Tirian, L., Lehotzky, A., Gelpi, E., Budka, H. and Ovádi J. (2004) Natively unfolded tubulin polymerization promoting protein TPPP/p25 is a common marker of alphasynucleinopathies. Neurobiol. Dis. 17, 155-162

Preusser, M., Lehotzky, A., Budka, H., Ovádi, J. and Kovacs, G. G. (2007) TPPP/p25 in brain tumours: expression in non-neoplastic oligodendrocytes but not in oligodendroglioma cells. Acta Neuropathol. 113, 213-215

Hoftberger, R., Fink, S., Aboul-Enein, F., Botond, G., Oláh, J., Berki, T., Ovádi, J., Lassmann, H., Budka, H. and Kovacs, G. G. (2010) Tubulin polymerization promoting protein (TPPP/p25) as a marker for oligodendroglial changes in multiple sclerosis. Glia 58, 1847-1857

Vincze, O., Oláh, J., Zadori, D., Klivenyi, P., Vécsei, L. and Ovádi, J. (2011) A new myelin protein, $\mathrm{TPPP} / \mathrm{p} 25$, reduced in demyelinated lesions is enriched in cerebrospinal fluid of multiple sclerosis. Biochem. Biophys. Res. Commun. 409, 137-141

45 Hasegawa, T., Baba, T., Kobayashi, M., Konno, M., Sugeno, N., Kikuchi, A., Itoyama, Y. and Takeda, A. (2010) Role of TPPP/p25 on alpha-synuclein-mediated oligodendroglial degeneration and the protective effect of SIRT2 inhibition in a cellular model of multiple system atrophy. Neurochem. Int. 57, $857-866$

Kawaguchi, Y., Kovacs, J. J., McLaurin, A., Vance, J. M., Ito, A. and Yao, T. P. (2003) The deacetylase HDAC6 regulates aggresome formation and cell viability in response to misfolded protein stress. Cell 115, 727-738

Li, G., Jiang, H., Chang, M., Xie, H. and Hu, L. (2011) HDAC6 alpha-tubulin deacetylase: a potential therapeutic target in neurodegenerative diseases. J. Neurol. Sci. 304, 1-8

Richter-Landsberg, C. and Leyk, J. (2013) Inclusion body formation, macroautophagy, and the role of HDAC6 in neurodegeneration. Acta Neuropathol. 126, 793-807 
Kopito, R. R. (2000) Aggresomes, inclusion bodies and protein aggregation. Trends. Cell. Biol. 10, 524530

50 Wenning, G. K., Stefanova, N., Jellinger, K. A., Poewe, W. and Schlossmacher, M. G. (2008) Multiple system atrophy: A primary oligodendrogliopathy. Ann. Neurol. 64, 239-246

51 Makioka, K., Yamazaki, T., Fujita, Y., Takatama, M., Nakazato, Y. and Okamoto, K. (2010) Involvement of endoplasmic reticulum stress defined by activated unfolded protein response in multiple system atrophy. J. Neurol. Sci. 297, 60-65

Kragh, C. L., Fillon, G., Gysbers, A., Hansen, H. D., Neumann, M., Richter-Landsberg, C., Haass, C., Zalc, B., Lubetzki, C., Gai, W. P., Halliday, G. M., Kahle, P. J. and Jensen, P. H. (2013) FAS-dependent cell death in alpha-synuclein transgenic oligodendrocyte models of multiple system atrophy. PLoS One 8, e55243

Danzer, K. M., Kranich, L. R., Ruf, W. P., Cagsal-Getkin, O., Winslow, A. R., Zhu, L., Vanderburg, C. R. and McLean, P. J. (2012) Exosomal cell-to-cell transmission of alpha synuclein oligomers. Mol. Neurodegener. 7, 42

\section{FIGURE LEGENDS}

Figure 1. Multiple interactions of TPPP/p25 with various ligands and proteins. The disordered TPPP/p25 displays high potency to induce tubulin assembly coupled with bundling activity. The in vitro phosphorylation of TPPP/p25 by specific protein kinases (CDK5, ERK2) strongly impedes its ability to promote the formation and bundling of intact microtubules. The binding of zinc ion induces structural rearrangement (molten globule formation) of $\mathrm{TPPP} / \mathrm{p} 25$ with increased tubulin polymerization promoting potency. GTP binding to TPPP/p25 shifts the monomer-dimer equilibrium towards dimer formation, which is a more compact species and has a more pronounced tubulin polymerization promoting potency than the disordered monomer. TPPP/p 25 specifically hydrolyses GTP in a $\mathrm{Mg}^{2+}$-dependent manner.

Figure 2. The effect of TPPP/p25 on microtubules. TPPP/p 25 modulates the stability of the microtubule system via its bundling and tubulin acetylation promoting activities influencing microtubule dynamics and stability, intracellular trafficking as well as aggresome formation. SIRT2: $\mathrm{NAD}^{+}$-dependent deacetylase sirtuin-2.

Figure 3. Physiological and pathological functions of the neomorphic moonlighting TPPP/p25. In normal brain TPPP/p25 is expressed in oligodendrocytes and plays a crucial role in the formation of projections in the course of differentiation requested for axon ensheathment. At pathological conditions altered TPPP/p25 expression was observed in distinct CNS diseases. Loss of TPPP/p25-positive oligodendrocytes within the plaques of human brain and significantly increased TPPP/p 25 level in the cerebrospinal fluid were found in patients suffering from multiple sclerosis. Lack of TPPP/p25 was revealed in gliome; while co-enrichment and co-localization of TPPP/p25 and alpha-synuclein have been reported in glial inclusions in the case of MSA. OLG: oligodendrocyte. 


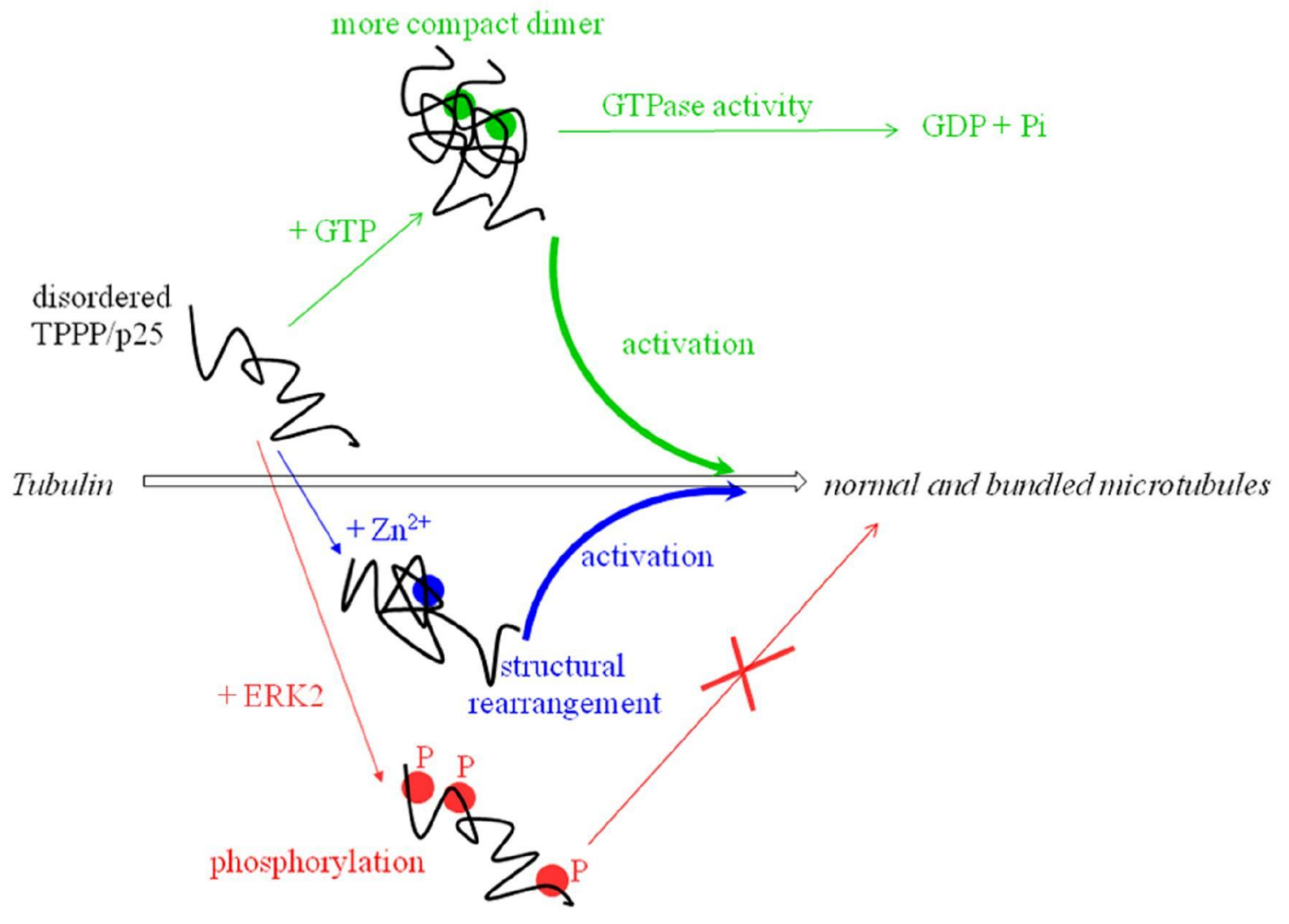




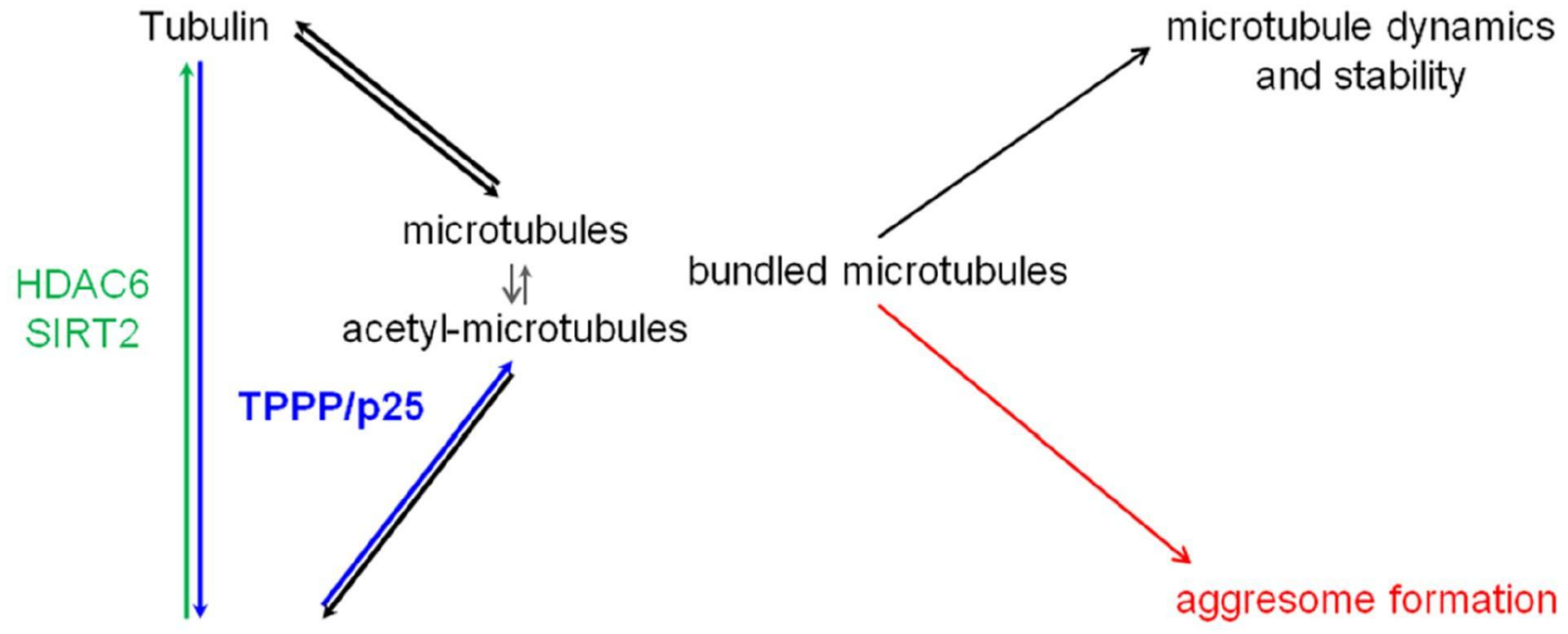

Acetyl-tubulin 


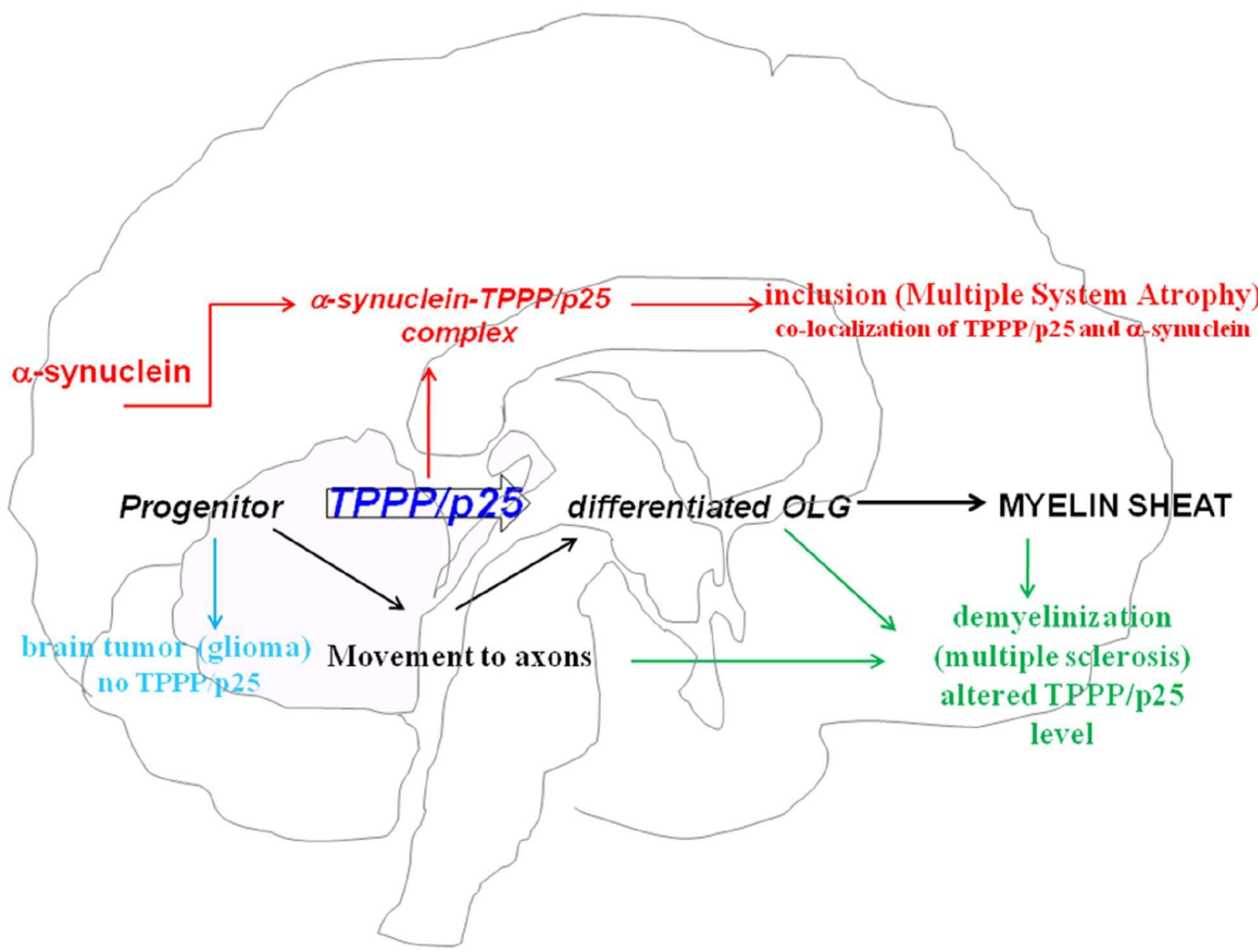

